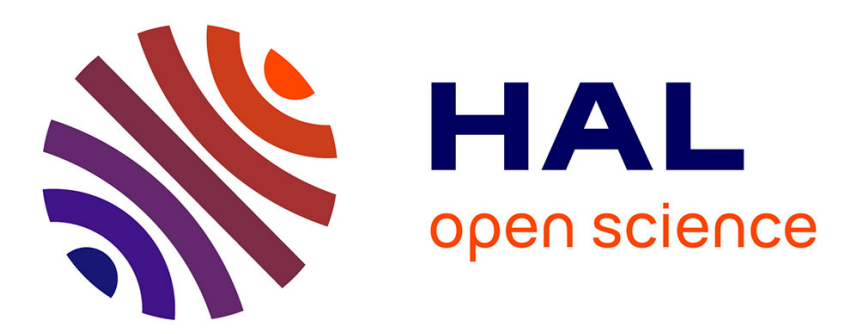

\title{
EXPERIMENTAL STUDY ON THE ELECTRIC FIELD OF DISLOCATIONS IN COLOURED ALKALI HALIDE CRYSTALS
}

\author{
G. Turchányi, M. Mátrai, J. Janszky, I. Tarján
}

\section{- To cite this version:}

G. Turchányi, M. Mátrai, J. Janszky, I. Tarján. EXPERIMENTAL STUDY ON THE ELECTRIC FIELD OF DISLOCATIONS IN COLOURED ALKALI HALIDE CRYSTALS. Journal de Physique Colloques, 1973, 34 (C9), pp.C9-261-C9-264. 10.1051/jphyscol:1973945 . jpa-00215420

\section{HAL Id: jpa-00215420 https://hal.science/jpa-00215420}

Submitted on 1 Jan 1973

HAL is a multi-disciplinary open access archive for the deposit and dissemination of scientific research documents, whether they are published or not. The documents may come from teaching and research institutions in France or abroad, or from public or private research centers.
L'archive ouverte pluridisciplinaire HAL, est destinée au dépôt et à la diffusion de documents scientifiques de niveau recherche, publiés ou non, émanant des établissements d'enseignement et de recherche français ou étrangers, des laboratoires publics ou privés. 


\title{
EXPERIMENTAL STUDY ON THE ELECTRIC FIELD OF DISLOCATIONS IN COLOURED ALKALI HALIDE CRYSTALS
}

\author{
G. TURCHÁNYI, M. MÁTRAI, J. JANSZKY and I. TARJÁN \\ Research Group for Crystal Physics of the Hungarian Academy of Sciences, Budapest
}

\begin{abstract}
Résumé. - Nous avons antérieurement mesuré le «spectre de photoconductivité de dislocation " dans la bande $\mathrm{F}$ dans des cristaux de $\mathrm{KCl}$ colorés aux rayons $\mathrm{X}$. Le spectre est interprété en supposant que le champ électrique interne des dislocations en mouvement perturbe les centres $F$, y produisant un effet Stark quadratique. En comparant nos résultats à ceux de Chiarotti, Grassano et al., nous avons estimé le champ interne dans notre cristal. Ce travail a également été effectué dans plusieurs autres halogénures alcalins.
\end{abstract}

Abstract. - Previously the "dislocation photoconduction spectrum " in the F band was measured by us in $\mathrm{X}$-ray coloured $\mathrm{KCl}$ crystals. The spectrum was interpreted by assuming that the internal electric field of moving dislocations perturbed the F-centres producing a quadratic Starkeffect in them. Comparing our results with Chiarotti, Grassano et al. we estimated the internal field in our crystal. This work was carried out on several other alkali halides as well.

In ionic crystals edge dislocations have an excess electric charge which is neutralized by the field of ions surrounding the dislocation. If these crystals are deformed in a suitable way an electric signal can be observed due to the movement of dislocations. According to some measurements, at deformation potentials of several thousand volts may appear on the surface of the crystals [1].

In the last few years we have been investigating the interaction of edge dislocations and point defects in X-irradiated alkali halide crystals approaching the problem from the side of dislocations. From our experimental results we obtained information on the magnitude of the internal dislocation electric field itself.

The dislocation photoconduction spectrum. - Our $X$-ray coloured, usually nominally pure alkali halide crystals were deformed by four-point bending and the exponential decay of the developed voltage upon illuminating the sample with light of constant intensity in the $F$ band was measured [2]. According to our experimental results the quantity a caracterizing the decay varies fairly linearly with the intensity of incident light and it is not in simple correlation with the amount of deformation and the F-center concentration. Plotting a/d against the wavelength $(\lambda)$ of the illuminating light we obtained the dislocation photoconduction spectrum (DPS) [3]. In principle this should follow the shape of the F optical absorption band by analogy with photoconductivity measurements carried out with an external electric field.

But as it can be seen in ligure I there is a marked difference between the DPS and the F optical absorption band [3-4].

The main differences:

1) The DPS is broadened compared to the F optical absorption band.

2) The DPS exhibits local maxima.

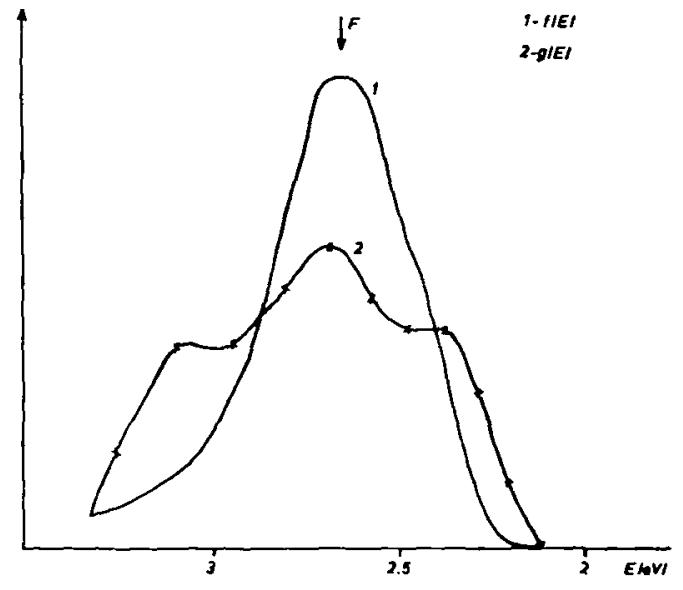

FlG. 1. - Dislocation photoconduction spectrum of a $\mathrm{NaCl}$ crystal (curve $-\times \longrightarrow$ ) and its $\mathrm{F}$ optical absorption band (curve - ).

In the present we are dealing mainly with the first feature of the DPS, for the second one we had given an explanation elsewhere [5].

For the interpretation of our spectra one had to assume that they were due to electrons released by the incident light from F-centers in the vicinity of dislocations, i. e. interacting with the electric field of dislocations. The fact that our spectra are essentially independent from the bulk concentration of F-centers in the range of $10^{15}-10^{17} \mathrm{~cm}^{-3}$ supports this idea too. Thus our method enables us to detect solely those F-centers which are interacting with dislocations.

Stark-effect of the F-center. - It is well known that at strong electric field causes a quadratic Starkeffect in the F-center. According to the theoretical considerations of Henry, Schnatterly and Slichter the effect can be easily analyzed by the method of moments of the absorption line shape [6]. 
The absorption band is characterized by the line shape function $f(E)$ ( $E$ is the photon energy), which is related to the absorption coefficient $(E)$ by

$$
(E)=C E f(E) \text {, }
$$

$C$ is a constant.

The application of an electric field changes the line shape function to $g(E)$. According to the theory the field leaves the zeroth and first moments unchanged

$$
\begin{gathered}
A=\int f(E) \mathrm{d} E=\int g(E) \mathrm{d} E, \Delta A=0 \\
<\Delta E>=0
\end{gathered}
$$

and causes a change of the second moment $\left\langle\Delta E^{2}\right\rangle$ which for light polarized in the field direction is proportional to the square of the local field strength $(F)$.

The change of the absorption coefficient at the peak of the $F$ band is related to the change of the second moment by the approximative relation:

$$
\frac{\Delta \alpha}{\alpha} \approx-\frac{\left\langle\Delta E^{2}\right\rangle}{\left\langle 2 E^{2}\right\rangle} \text {. }
$$

Therefore

$$
\left|\frac{\Delta \alpha}{\alpha}\right| \alpha F^{2} \text { too . }
$$

The experimental results of Chiarotti, Grassano et al. [7] and those of Rhyner and Cameron [8] supported the HSS theory and plotting $\Delta \alpha / \alpha$ against

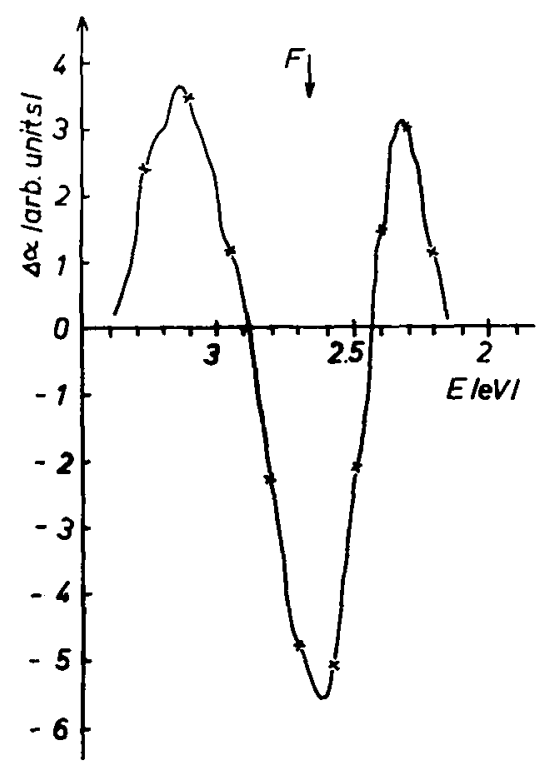

(a)

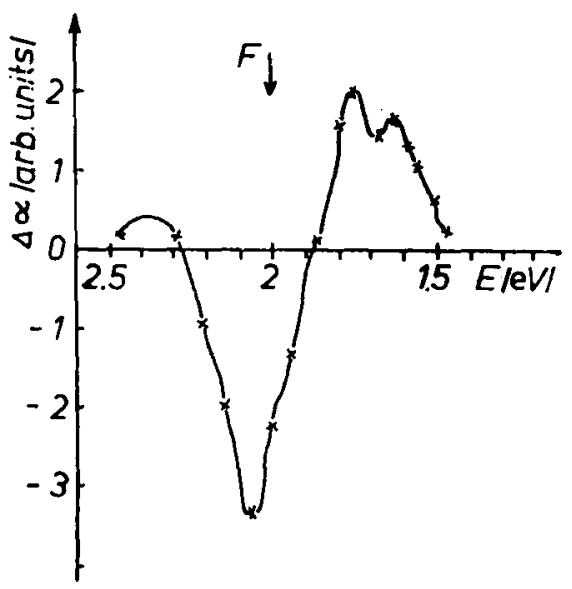

(c)

FIG. 2. - Difference curves $g(E)-f(E)$ for $a) \mathrm{NaCl} ; b) \mathrm{KCl}$; c) $\mathrm{KBr}$; d) $\mathrm{KI}$ crystals.

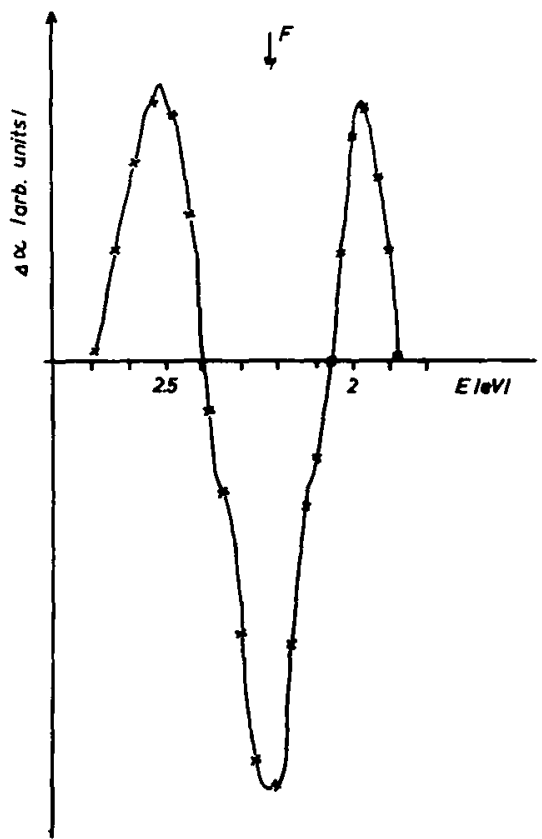

(b)

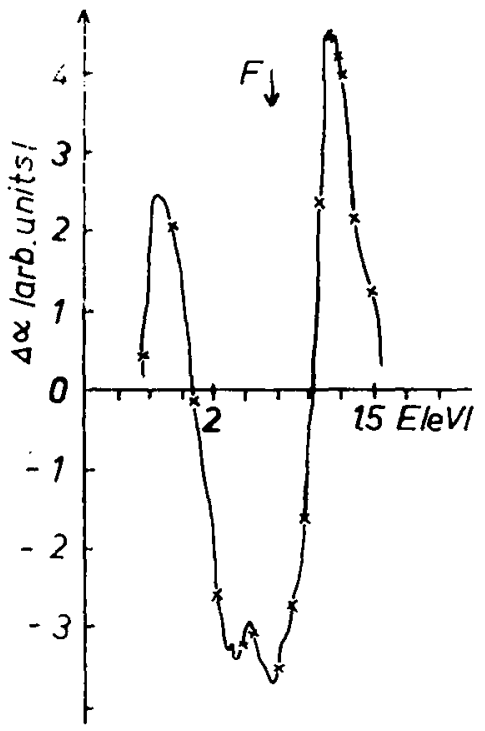

(d) 
the square of the field strength they obtained the expected straight line.

Results and discussion. - We assumed, that in our case we were dealing with the Stark-effect of the F-center caused by the dislocation electric field, and as an approximation the HSS theory is applicable to our measurements too. According to the theory the zeroth and first moments of the $\mathrm{F}$ band perturbed by the dislocation electric field remain unchanged, and based on this the $g(E)-f(E)$ difference curves were constructed, where $f(E)$ is the line shape function of the unperturbed $\mathrm{F}$ band and $g(E)$ is the line shape function of the DPS. Figures $2 a, b, c, d$ show these for $\mathrm{NaCl}, \mathrm{KCl}, \mathrm{KBr}$ and $\mathrm{KI}$ crystals.

From the difference curves and the $F$ band the value of $\Delta x / \alpha$ in the peak of the $F$ band was determined. Than extrapolating the experimental results obtained for $\Delta \alpha / \alpha\left(F^{2}\right)$ with an external electric field [7] we obtained the following local electric field values for our crystals.

\section{TABLE}

$\begin{array}{lcc}\text { Crystal } & \Delta \alpha / \alpha\left(^{*}\right) & \begin{array}{c}\text { Internal electric field } \\ {[\mathrm{V} / \mathrm{cm}]}\end{array} \\ \mathrm{NaCl} & 0.367 & 1.05 \times 10^{7} \\ \mathrm{KCl} & 0.381 & 5.0 \times 10^{6} \\ \mathrm{KBr} & 0.359 & 3.5 \times 10^{6} \\ \mathrm{KI} & 0.242 & 5.2 \times 10^{6}\end{array}$

(*) At the peak of the $F$ band.

The values given in the table were obtained from measurements carried out on one sample in case of all crystals. The scattering of the internal electric field values obtained on the same sample at different measurement was within $8 \%$ as we could ascertain

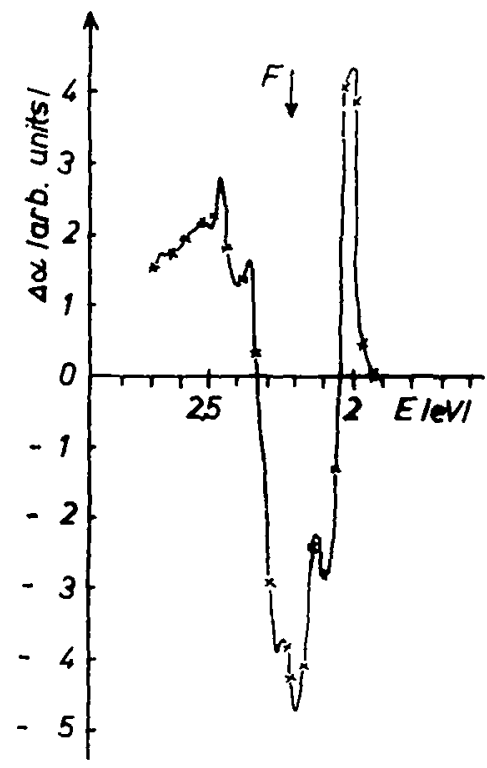

FIG. 3. - Difference curve of an extremely pure $\mathrm{OH}$-free $\mathrm{KCl}$ crystal.

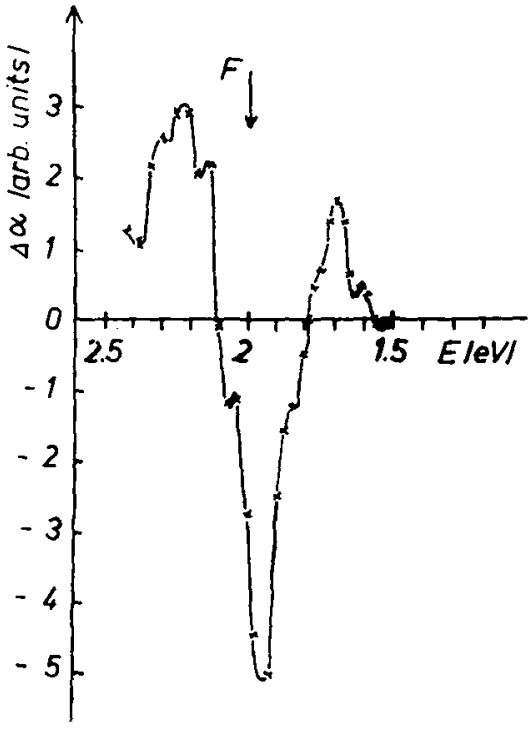

FIG. 4. - Difference curve of an extremely pure $\mathrm{OH}-$ free $\mathrm{KBr}$ crystal.

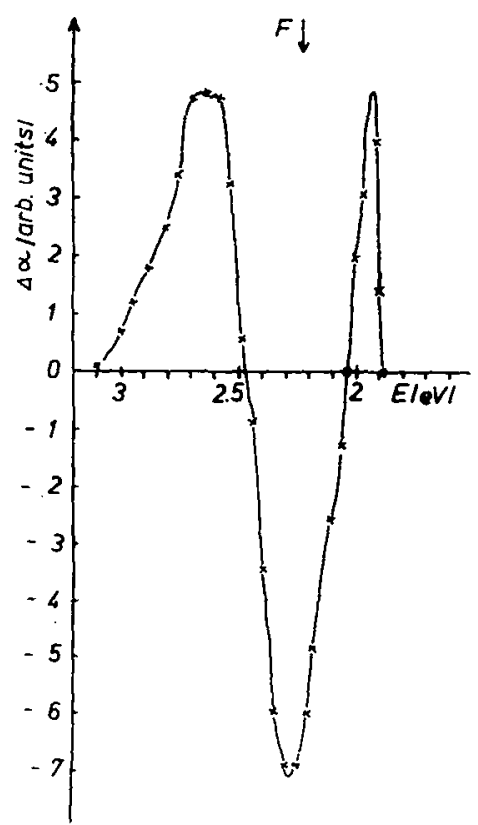

FIG. 5. - Difference curve of an additively coloured $\mathrm{KCl}$ crystal.

for the case of $\mathrm{KCl}$. Measurements on different samples of the same alkali halide gave field strength values varying only within $20 \%$. Extremely pure OH-free crystals and crystals coloured additively gave also essentially the same results (Fig. 3, 4, 5).

Our results should be considered approximative ones, due to the following:

1) The field in the vicinity of dislocations is inhomogeneous, we determined only a resultant average value.

2) The condition of illumination with light of constant intensity is not satisfied through the whole 
thickness of the sample. This error is diminished probably by the light scattering within the sample and reflection from internal surfaces.

3) The local maxima of the DPS explainable by lattice distortion around dislocations, appear simultaneously with the electric field effect making the results more complex and the interpretation more difficult.
4) Our measurements were carried out at room temperature while those carried out with an external electric field at low temperature. This, due to the variation of $\left\langle E^{2}\right\rangle$ with temperature should modify our values obtained for $F$ by a factor of 2 .

5) One expects that impurities should play an important role in the DPS, this problem is now under investigation.

\section{References}

[1] Whitworth, R. W., Phil. Mag. 10 (1964) 801.

[2] Turchányi, G., Mátrai, M. and TARJÁn, I., Revlue Roumaine de Physique 13 (1968) 59.

[3] TurchányI, G. and Tarján, I., Acta Physica Hungarica 28 (1970) 291.

[4] TuRchányI, G., Janszky, J., Mátrai, M. and TARJÁn, I., Phys. Stat. Sol. 38 (1970) K 35.

[5] Turchányi, G., Janszky, J., Mátrai, M. and TaRJán, Y., Kristallografiya 17 (1972) 426.
[6] Henry, C. H., Schnatterly, S. E. and Schlichter, C. P., Phys. Rev. 137 (1965) A 583.

[7] Chiarotti, G., Grassano, U. M. and Rosei, R., Phys. Rev. Lett. 17 (1966) 1043.

Grassano, U. M., Margaritondo, G., Rosei, R., Phys. Rev. B 2 (1970) 3319.

[8] Rhyner, Ch. R. and Cameroun, J. R., Phys. Rev. 169 (1968) 710 . 